\title{
Combining Microbubbles and Ultrasound for Drug Delivery to Brain Tumors: Current Progress and Overview
}

\author{
Hao-Li Liu ${ }^{1}$, Ching-Hsiang Fan², Chien-Yu Ting², and Chih-Kuang Yeh², ${ }^{2}$ \\ 1. Department of Electrical Engineering, Chang-Gung University, 259 Wen-Hwa 1st Road, Kuei-Shan, Tao-Yuan, Taiwan 33302 \\ 2. Department of Biomedical Engineering and Environmental Sciences, National Tsing Hua University, No. 101, Section 2, Kuang-Fu Road, \\ Hsinchu, Taiwan 30013
}

\begin{abstract}
$\triangle$ Corresponding author: Department of Biomedical Engineering and Environmental Sciences, National Tsing Hua University, No. 101, Section 2, Kuang-Fu Road, Hsinchu, Taiwan 30013. Tel: +886-3-571-5131 ext. 34240; Fax: +886-3-571-8649. E-mail: ckyeh@mx.nthu.edu.tw

(c) Ivyspring International Publisher. This is an open-access article distributed under the terms of the Creative Commons License (http://creativecommons.org/ licenses/by-nc-nd/3.0/). Reproduction is permitted for personal, noncommercial use, provided that the article is in whole, unmodified, and properly cited.
\end{abstract}

Received: 2013.1 I.07; Accepted: 2014.01.20; Published: 2014.02.12

\begin{abstract}
Malignant glioma is one of the most challenging central nervous system (CNS) diseases, which is typically associated with high rates of recurrence and mortality. Current surgical debulking combined with radiation or chemotherapy has failed to control tumor progression or improve glioma patient survival. Microbubbles (MBs) originally serve as contrast agents in diagnostic ultrasound but have recently attracted considerable attention for therapeutic application in enhancing blood-tissue permeability for drug delivery. MB-facilitated focused ultrasound (FUS) has already been confirmed to enhance CNS-blood permeability by temporally opening the blood-brain barrier (BBB), thus has potential to enhance delivery of various kinds of therapeutic agents into brain tumors. Here we review the current preclinical studies which demonstrate the reports by using FUS with MB-facilitated drug delivery technology in brain tumor treatment. In addition, we review newly developed multifunctional theranostic MBs for FUS-induced BBB opening for brain tumor therapy.
\end{abstract}

Key words: Microbubbles, brain tumor, focused ultrasound, blood-brain barrier, chemotherapy

\section{Brain Tumors and the Blood-Brain Barrier}

\section{I.I Current status of brain glioma treatment}

Nearly 20,000 patients in the U.S. are diagnosed annually with primary malignant brain cancers, among which more than $50 \%$ are reported as glioblastoma multiforme (GBM), making this the most common malignant brain cancer in adults, and it is responsible for half of cancer patients' deaths [1]. Gliomas can be divided into astrocytic and oligodendroglial tumor types, and are classified as grades I to IV based on the tumor growth rate. The median survival times are reportedly 5-15 years and 9-12 months in patients with low- and high-grade gliomas, respectively $[2,3]$.
GBM patients first undergo debulking surgery to remove most of the tumor mass, followed by chemotherapy and/or radiation therapy. A phase-III randomized trial found that the prognosis of GBM patients remains poor after debulking surgery and radiation, with a median survival time of only 12 months [4]. Chemotherapy is considered to be an important treatment modality for malignant brain tumors [5]. The most common adjuvant chemotherapy drugs to be administered systemically are carmustine (also called BCNU), PCV (comprising procarbazine, lomustine, and vincristine), and the first-line chemotherapeutic agent temozolomide (TMZ). However, such chemotherapeutic drugs provide a limited and short-duration response, typically resulting in disease 
stabilization that lengthens survival by only a few months. In addition, the side effects of chemotherapy negatively impact the already poor quality of life during the patient's remaining life span. Up to date no specific drug or regimen has shown superior efficacy in GBM treatment, and delivery methods of chemotherapeutic agents to treat GBM have met with limited success. The dilemma is that while increasing the concentration at which a chemotherapeutic agent is administered in an attempt to increase the dose delivered to the tumor may improve the treatment outcome, this is likely to also result in substantial systemic toxicity [6]. There is therefore an urgent need to develop techniques for delivering a chemotherapeutic agent into the central nervous system (CNS) so that it reaches a sufficiently high therapeutic dose in the targeted brain tumor region while minimizing its systemic concentration.

\section{I.2 The blood-brain barrier in brain tumors}

The blood-brain barrier (BBB) is a highly specialized structure in CNS blood vessels and capillaries that comprises arachnoid membranes, cerebral capillary endothelial cells, and the choroid plexus epithelium. These layered cell structures construct the so-called tight junctions also known as the zonula occludens (Fig. 1) [7]. The tight junctions of the cerebrovascular endothelium contain membrane-associated guanylate kinases such as ZO-1 and ZO-2, cadherins (single-pass membrane-spanning molecules), and cingulin [8]. In addition to tight junctions, the low endocytic activity and absence of fenestrations also limit transcellular transport. By forming an almost impermeable barrier to the diffusion of large (>200 kDa) and hydrophobic molecules, the BBB not only protects the normal brain parenchyma from foreign toxic substances, but also blocks the delivery of many potentially effective diagnostic or therapeutic agents in cases of CNS disease [9]. The normal physiological function of the BBB therefore needs to be temporarily disrupted to allow the diffusion or local delivery of macromolecular therapeutic or diagnostic agents into the brain.

The integrity of the BBB is typically highly heterogeneous within tumor tissue, resulting in highly variable BBB permeability within different areas of the same tumor. Brain tumors are usually most permeable in the tumor core whereas the BBB remains relatively intact at the tumor peripheral regions [10]. The BBB of the peripheral glioma has been shown to remain highly functional [11-13], and previous clinical studies have demonstrated that brain tumor cells can migrate great distances from the enhancing regions of the tumors $[14,15]$. The intact BBB of tumor-infiltrating regions (mostly the tumor periphery) severely restricts treatment efficacy and is a critical factor in the high rate of GBM recurrence. For this reason, enhancing the BBB permeability of the tumor periphery represents an important potential strategy for improving treatment efficacy.

\section{I.3 BBB-disrupting strategies for enhanced drug delivery to brain tumors}

Several clinical and preclinical methods exist for delivering chemotherapeutic agents for GBM treatment. Intravenously (IV) administered agents reach the brain tissues from either the blood or cerebrospinal fluid (CSF) after penetrating the BBB or blood-CSF barrier.

Interstitial delivery involves either IV injection [16] or the implantation of biodegradable wafer-containing drugs attached inside surgically removed brain-tumor cavities [17, 18] to bypass the impermeable BBB. In a 240-patient clinical trial the median survival time was 14 months for implantation of a BCNU wafer compared to about 12 months for placebo [18]. Similar results were obtained for Gliadel $^{\circledR}$, but its use was associated with various adverse effects, including intracranial hypertension, CSF leakage, brain edema, seizures, intracranial infection, and abnormal healing [19].

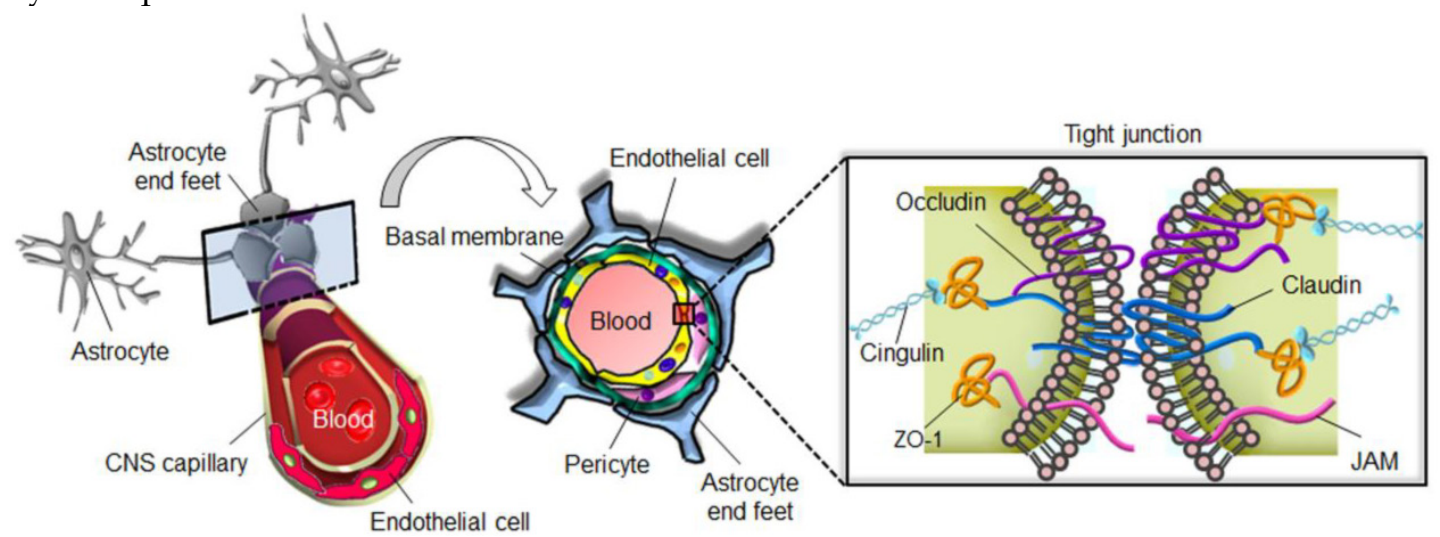

Fig. I. The blood-brain barrier prevents diffusion of harmful molecules as well as the delivery of therapeutic drugs to the brain. 
High-concentration chemotherapeutic agent administration obtained by interstitial infusion (or so-called convection-enhanced delivery) has also been reported, where a pressure gradient is used to generate continuous bulk fluid flow through the brain interstitium [20]. The distribution of the chemotherapeutic agent depends on its molecular weight, total concentration, and polarity, as well as the total volume infused and the rate of infusion. Current challenges include heterogeneous drug distributions and high or varying tumor interstitial fluid pressures, which can lead to faster drug efflux out of the injection site and thereby significantly degrade the efficacy.

BBB permeability can also be increased by intra-arterial osmotic agents or hypertonic solutions [11, 21, 22]. Phase-II patient trials have demonstrated that therapeutic outcomes are enhanced when the BBB permeability is higher (expected survival of 17.5 vs. 11.4 months). However, a major obstacle of using osmotic pressure to increase BBB permeability is the lack of specific targeting. Complications include neurological deficits, syndromes similar to stroke, possible migration of tumor cells, temporal seizures, and new tumor-nodule formation at distant brain locations [23]. Current strategies for enhanced drug delivery have therefore been limited by their invasiveness and/or lack of specific targeting.

\section{Current Status of Microbubbles and their use to Enhance Drug Delivery to the Brain}

\section{I Microbubbles as ultrasound contrast agents}

The use of microbubbles (MBs) in echocardiography was first reported in 1968 [24]. Due to the absence of shell structures, these MBs had short half-lives (within a few seconds) that limited their clinical applications. Updated MB designs have led to higher stability through increased molecular weight, low solubility, incorporation of a low-diffusivity gas such as nitrogen or perfluorocarbon, and use of a biodegradable shell material such as albumin, phospholipids, or polymers $[25,26]$. MBs are highly echo- genic in vivo due to the mismatch in acoustic impedance (i.e., the product of density and speed of sound) between their gas cores and surrounding tissues [27]. IV administered MBs are capable of increasing the intensity of backscattered ultrasound by up to 20-30 $\mathrm{dB}$ [28], therefore serving as excellent ultrasound imaging contrast agents. MBs are currently applied in routine clinical examinations including organ perfusion and enhanced diagnosis in highly vascularized tumor structures $[25,29]$, and in diagnoses of cardiovascular and renal diseases [30, 31].

At present, three commercial MB agentsOptison $^{\mathrm{TM}}$ (GE Healthcare, WI, USA), Definity ${ }^{\circledR}$ (Lantheus Medical Imaging, MA, USA), and SonoVue ${ }^{\circledR}$ (Bracco, Milano, Italy)-are licensed for clinical diagnostic applications (Table 1). The commercial MBs in these agents are typically larger than 1 $\mu \mathrm{m}$ and have imaging durations within the range of 5-10 min.

\subsection{Therapeutic applications of MBs}

In addition to their contrast-enhancing ability for diagnostic applications, MBs also possess unique properties for therapeutic applications [32-34]. MBs excited by ultrasound are capable of physically interacting with surrounding media through stable or inertial cavitation (Fig. 2). Stable cavitation generated by ultrasound excitation causes repetitive MB contraction and expansions that induce the flow of liquid around the MBs (called microstreaming) that in turn applies shear stress to cell membranes, leading to ion channel/receptor modulation and therefore affects on cell permeability [35]. On the other hand, in inertial cavitation the excessive ultrasound pressure causes abrupt MBs destruction or collapse to produce strong mechanical stress (i.e., shock waves), microstreaming, microjets [36], or even free radical production [37] in the surrounding media. Shock waves and micro-jets are strong forces that cause cell membrane perforation and even blood vessel permeabilization $[38,39]$. Recently, the use of MBs in conjunction with non-thermal pulsed-mode ultrasound has been investigated to enhance blood-tissue drug permeability for therapeutic applications [40-43].

Table I. Specifications of commercial and self-made microbubbles.

\begin{tabular}{|c|c|c|c|c|c|c|}
\hline $\begin{array}{l}\text { MB } \\
\text { type }\end{array}$ & Manufacturer & Shell material & Gas & Mean size $(\mu \mathrm{m})$ & $\begin{array}{l}\text { Concentration } \\
\text { (bubbles/mL) }\end{array}$ & $\begin{array}{l}\text { MB half-life } \\
\text { (minutes) }\end{array}$ \\
\hline Optison ${ }^{\mathrm{TM}}$ & GE Healthcare & Albumin & $\mathrm{C}_{3} \mathrm{~F}_{8}$ & $2.0-4.5$ & $5.0-8.0 \times 10^{8}$ & $2.5-4.5$ \\
\hline Definity ${ }^{\circledR}$ & Lantheus Medical Imaging & Phospholipid & $\mathrm{C}_{3} \mathrm{~F}_{8}$ & $1.1-3.3$ & $1.2 \times 10^{10}$ & $2-10$ \\
\hline SonoVue ${ }^{\circledR}$ & Bracco & Phospholipid & $\mathrm{SF}_{6}$ & $2-8$ & $0.9-6 \times 10^{9}$ & $3-6$ \\
\hline Lipid MBs [103] & Self-made & $\begin{array}{l}\text { Phospholipid/ } \\
\text { Lipo-polymer }\end{array}$ & $\mathrm{C}_{3} \mathrm{~F}_{8}$ & $0.2-0.7$ & $1.4-3.0 \times 10^{10}$ & $10-20$ \\
\hline BCNU-loaded MBs [103] & Self-made & Phospholipid & $\mathrm{C}_{3} \mathrm{~F}_{8}$ & $1.32 \pm 0.18$ & $19.78 \pm 4.9 \times 10^{9}$ & $10-20$ \\
\hline $\begin{array}{l}\text { Antiangiogenic BCNU-loaded } \\
\text { MBs [104] }\end{array}$ & Self-made & Phospholipid & $\mathrm{C}_{3} \mathrm{~F}_{8}$ & $1.79 \pm 0.13$ & $12.29 \pm 0.25 \times 10^{9}$ & $10-20$ \\
\hline SPIO-DOX -loaded MBs [105] & Self-made & Phospholipid & $\mathrm{C}_{3} \mathrm{~F}_{8}$ & $1.04 \pm 0.01$ & $3.25 \pm 0.30 \times 10^{10}$ & $10-20$ \\
\hline
\end{tabular}




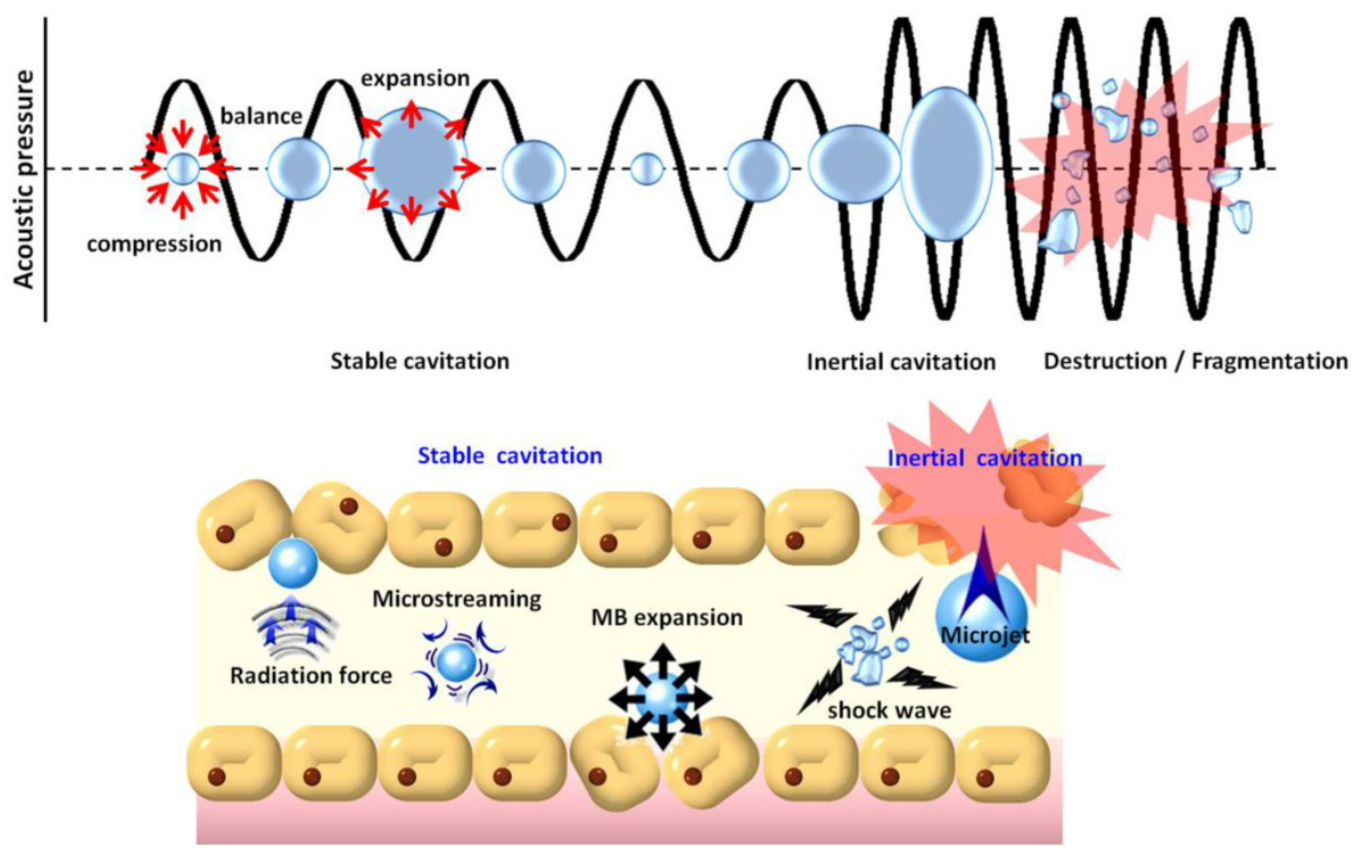

Fig. 2. Physical mechanisms underlying the biological effects induced when microbubbles are excited by ultrasound energy.

\section{MB-facilitated Focused-Ultrasound- Induced BBB Opening}

\section{I Concepts of MB-facilitated focused- ultrasound-induced BBB opening for CNS drug delivery}

Treatment with non-thermal burst-mode ultrasound in the presence of MBs has been confirmed to be able to induce local and reversible BBB opening due to the disruption of tight junctions in CNS capillaries (Fig. 2) [44-46]. Noteworthy, the size and resonance frequency of MBs (in general, the smaller the size of MBs, and the higher the resonance frequency of MBs) were reported to be critical in MB-facilitated focused-ultrasound (FUS)-induced (MB-FUS) BBB opening. Larger MBs (such as SonoVue ${ }^{\mathrm{TM}}$ ) allow sufficient size expansion to stimulate vessel walls, and thereby BBB opening can be achieved with a lower acoustic pressure. When MBs collapse inside a blood vessel, smaller ones $(<2 \mu \mathrm{m})$ would be likely to be fragmented at some distance from the endothelial wall, whereas larger MBs would expand and fragment while in contacting with endothelial walls, and may increase the occurrence of endothelial cell destruction, capillary lumen damage, or erythrocyte extravasations due to inertial cavitation $[47,48]$

The abilities of several types of molecules to penetrate the intact BBB upon MB-FUS BBB opening in preclinical settings have been investigated. Trypan blue (872 Da) and Evans blue (960 Da) are dyes that are widely used to identify the BBB opening region $[49,50]$. In addition, gadolinium-based contrast agents such as Gd-DTPA (573-928 Da) used in magnetic resonance imaging (MRI) imaging are commonly administered to monitor the location and efficacy of BBB opening [44-46].

Various other imaging tracers have been delivered across the $\mathrm{BBB}$, including horseradish peroxidase $(40 \mathrm{kDa})[45,51]$, monocrystalline iron oxide nanoparticles $(20 \mathrm{~nm}, 10 \mathrm{kDa})$ [51], Alexa Fluor 488 (10 kDa) [52], Texas-Red-tagged dextran (3-70 kDa) [47, 54-56], lanthanum chloride (139 Da) [57], 99mTc diethylenetriamine pentaacetate $(492 \mathrm{Da})[58,59]$, superparamagnetic iron oxide (SPIO, $60 \mathrm{~nm})[60,61]$, ionic manganese [62], and gold nanorods [63].

Compared to alternative brain drug delivery strategies such as hypertonic infusion [23] and the use of modified lipophilic chemicals, MB-FUS is an entirely noninvasive procedure capable of local rather than systemic BBB disruption, thus minimizing off-target effects. The reversibility of this BBB-disrupting method provides a time window of several hours for drug release, allowing enhanced permeability and retention of the drug specifically in the tumor region [64-66]. MB-FUS thus provides an attractive alternative for elevating the local concentration of chemotherapeutic agents for the treatment of CNS diseases.

\subsection{MB-FUS BBB opening for delivery of therapeutic substances to the brain}

Therapeutic molecules have been shown to penetrate the intact $\mathrm{BBB}$ of the normal brain upon MB-FUS BBB opening in preclinical settings. Both 
Herceptin (150 kDa) and D4 receptor antibodies (150 $\mathrm{kDa})$ have been successfully delivered to mouse brains [67]. Doxorubicin (DOX; $543 \mathrm{Da}$ ) has been delivered into the normal rat brain via MB-FUS BBB opening [64], and the amount of methotrexate (545 Da) delivered to the brain was significantly higher for FUS-BBB disruption than for an intra-carotid injection [68]. Therapeutic anti-amyloid- $\beta$ antibodies (150 kDa) which were applied to remove $A \beta$ plagues for immunotherapy in Alzheimer's disease treatment have been successfully delivered to the brain [69, 70]. Macromolecules such as magnetic nanoparticles (comprising 60-nm SPIO) have also been successfully delivered into the brains of both small and large animals via BBB opening [60, 71, 72]. Polyethylene-glycol-coated gold nanoparticles (10-20 nm) have recently been delivered into the normal rat brain, which could have potential photother$\mathrm{mal} /$ photoacoustic imaging applications for combined cancer treatment and diagnosis [63]. Enhanced delivery of boronophenylalanine which has high thermal neutron capture cross-section for boron neutron-capture therapy (BNCT) has been achieved via MB-FUS BBB opening, indicating that this technique has potential in increasing the treatment efficiency of BNCT [73, 74]. Small interfering RNA (13 kDa) has been non-invasively delivered into the striatum to modulate the expression of mutant Huntingtin protein [61, 75]. More recently, stem cells were also delivered to brain tissues using a BBB opening technique $[76,77]$.

The above studies have demonstrated a wide variety of possible applications of MB-FUS BBB opening for CNS disease treatment; however, the application to brain tumor treatments constitutes the largest proportion ( $>25 \%$ ) of preclinical investigations using this approach. The following section provides a comprehensive overview of the current progress of MB-FUS BBB opening applied in brain tumor animal models to confirm the therapeutic efficacy associated with the enhanced delivery of chemotherapeutic agents.

\section{MB-FUS BBB Opening for Brain Tumor Therapy}

The efficacy of brain tumor treatment with enhanced delivery of chemotherapeutic drugs by MB-FUS BBB opening has been evaluated in a preclinical setting with liposomal DOX, BCNU, and TMZ, as described in Sections 4.1-4.3, respectively.

\section{I MB-FUS BBB opening to enhance liposomal DOX delivery}

The earliest attempt at FUS-enhanced delivery for glioma treatment involved DOX in the form of
Doxil $^{\circledR}$ (Ben Venue Laboratories, OH, USA), which was encapsulated in long-circulating pegylated liposomes [64, 78, 79] (frequency $=1.7 \mathrm{MHz}$, acoustic pressure $=1.2 \mathrm{MPa}$, burst length $=10 \mathrm{~ms}$, pulse repetition frequency $(\mathrm{PRF})=1 \mathrm{~Hz}$, and sonication duration $=60-120 \mathrm{~s}$ ). Therapeutic efficacy was evaluated in rats implanted with 9L-glioma-cell tumors by comparing population survival curves among different treatment groups. Longitudinal MRI used to follow the tumor progression revealed that tumor growth in rats with implanted glioma after treatment with MB-FUS+Doxil was delayed compared to control-tumor and Doxil-alone tumor animal groups; the last group showed continued tumor growth after treatment. Median survival was improved $16 \%$ relative to control animals by Doxil-alone treatment, and was further improved to $24 \%$ by additional MB-FUS treatment (control, 25 days; FUS alone, 25 days; Doxil alone, 29 days; MB-FUS+Doxil, 31 days). The average tumor volume doubling times $\left(\mathrm{T}_{1 / 2}\right)$ were 3.7, 2.2, 2.3, and 2.7 days in the MB-FUS+Doxil, FUS-alone, control, and Doxil-alone groups, respectively. One recent study adopting multiple treatments involving combined MB-FUS BBB opening and Doxil delivery has also demonstrated significant improvements in treatment outcomes [80].

\subsection{MB-FUS BBB opening to enhance BCNU delivery}

MB-FUS-enhanced BCNU delivery was also investigated in the present study [81]. BCNU has been used clinically for many years as a chemotherapeutic agent for the treatment of gliomas [82]. Although BCNU is lipophilic, which allows it to penetrate the BBB structure, its substantial toxicity limits the overall dose and thus the concentration in the tumor. Only a modest benefit in survival has been shown in clinical trials compared to radiation therapy alone; the median survival improvement was shown to be limited, which improved from 9.4 months for radiation alone to 12 months for combined radiation and $\mathrm{BCNU}$ treatment [83].

Using the in-house-developed integrated MRI-monitored FUS platform to investigate enhanced delivery of $\mathrm{BCNU}$ in mice (frequency $=400 \mathrm{kHz}$, acoustic pressure $=0.62 \mathrm{MPa}$, burst length $=10 \mathrm{~ms}$, $\mathrm{PRF}=1 \mathrm{~Hz}$, and sonication duration $=30 \mathrm{~s}$ ), we found a nearly twofold FUS-dependent increase (from 170 to $344 \mu \mathrm{g})$ in the dose of BCNU at the tumor. Without pre-sonication, the BCNU concentration was similar in healthy and tumor-bearing brain sites (170 vs. 150 $\mu \mathrm{g})$. Tumors in the FUS-alone group grew about threefold during the observation period (with the progression period of 20 days), which was similar to that in the control group (about 2.5-fold). Treatment 
with BCNU alone also resulted in a similar tumor progression. Combining MB-FUS and BCNU was reported to exert the largest tumor-suppressing effect. Moreover, MB-FUS+BCNU also increased the median survival time to over 50 days, compared to 29,26 , and 32 days in the control, MB-FUS-alone, and BCNU-alone groups, respectively. The application of MB-FUS to enhance BCNU delivery to brain tumors therefore appears to suppress tumor growth as well as prolong animal survival relative to the use of either treatment alone.

\subsection{MB-FUS BBB opening to enhance TMZ delivery}

TMZ is an alkylating agent that was approved for the treatment of newly diagnosed or recurrent brain tumors in 2005 [84, 85]. TMZ is an imidazotetrazine derivative that spontaneously converts to monoethyl triazenoimidazole carboxamide, which is the active metabolic product of both TMZ and dacarbazine. TMZ has the potential advantage of being absorbed orally and then entering the CNS [86]. Recent TMZ phase-III trials showed more promising results, with a clinically significant improvement in the 2-year survival rate of $26.5 \%$ (median survival time of 15 months) for radiotherapy plus TMZ compared to radiation alone [87].

We also recently demonstrated enhanced TMZ delivery by MB-FUS BBB opening [88]. In that study, liquid chromatography-tandem mass spectrometry (MS) was used to measure the TMZ levels in both CSF and plasma. We showed that combining MB-FUS significantly increased the TMZ CSF/plasma ratio from $22 \%$ to $39 \%$ compared to TMZ alone (frequency $=500 \mathrm{kHz}$, acoustic pressure $=0.6 \mathrm{MPa}$, burst length $=$ $10 \mathrm{~ms}, \mathrm{PRF}=1 \mathrm{~Hz}$, and sonication duration $=60 \mathrm{~s}$ ). The tumor progression over 7 days showed a significant control effect, with the tumor progression ratio reducing from 24 to only 5. Animals receiving high-dose TMZ showed controlled tumor progress, however, their survival was not extended. In contrast, combined delivery of a reduced dose of TMZ (75 mg/ $\mathrm{kg}$ per day, 5 days total) with MB-FUS was shown to extend the animal survival significantly compared to control (100 mg/ kg per day, 5 days total) (improvement in the median survival time of $15 \%$; Table 2 ).

Table 2. Summary of using MB-FUS BBB opening for preclinical brain tumor therapy.

\begin{tabular}{|c|c|c|c|c|c|}
\hline Author, Year & MBs type & Animal model & Substance delivered & Study conclusion & Ref. \\
\hline $\begin{array}{l}\text { Treat et el, 2007, } \\
2012\end{array}$ & Optison & Rat 9L glioma model & Liposomal-DOX [70-100 nm] & $\begin{array}{l}\text { MB-FUS + Liposomal-Dox delivery controlled tumor progression } \\
\text { and improved animal survival }\end{array}$ & {$[78,79]$} \\
\hline Liu et al., 2010 & Sonovue & Rat C6 glioma model & $\begin{array}{l}\text { Evans Blue [960 Da], BCNU } \\
{\left[214 \mathrm{Da}^{*}\right]}\end{array}$ & $\begin{array}{l}\text { Unfocused low-frequency }(28-\mathrm{kHz}) \text { US with } 6-10 \text { min exposure } \\
\text { Obtain wide areas of BBB opening and low incidence of hemor- } \\
\text { rhagic complications }\end{array}$ & [111] \\
\hline Liu et al., 2010 & Sonovue & Rat C6 glioma model & $\begin{array}{l}\text { BCNU [214 Da], Evans Blue } \\
{\left[960 \mathrm{Da}^{*}\right], \text { Magnevist }[928} \\
\mathrm{Da}]\end{array}$ & $\begin{array}{l}\text { Delivery of chemotherapeutic agent BCNU } \\
\text { MB-FUS + BCNU provide better tumor progression control and } \\
\text { animal median survival improved by } 72 \%\end{array}$ & [81] \\
\hline Liu et al., 2010 & Sonovue & Rat C6 glioma model & $\begin{array}{l}\text { Epirubicin [544 Da], MNP } \\
{[6-12 \mathrm{~nm}], \text { Evans Blue [960 }} \\
\text { Da *], Magnevist [928 Da] }\end{array}$ & $\begin{array}{l}\text { Delivery of chemotherapeutic agent Epirubicin conjugated on } \\
\text { magnetic nanoparticle } \\
\text { Epirubicin-loaded MNPs + FUS + MT increase in MNP delivery } \\
\text { and slowed tumor growth }\end{array}$ & [106] \\
\hline Chen et al., 2010 & Sonovue & Rat C6 glioma model & $\begin{array}{l}\mathrm{BCNU}[214 \mathrm{Da}], \mathrm{BCNU} \text { on } \\
\mathrm{Fe}_{3} \mathrm{O}_{4} \mathrm{SPAnH} \text { nanoparticles } \\
{[10-20 \mathrm{~nm}], \text { Magnevist [928 }} \\
\mathrm{Da}]\end{array}$ & $\begin{array}{l}\text { Delivery of chemotherapeutic agent BCNU conjugated with } \\
\text { magnetic Fe3O4SPAnH particles following FUS and magnet } \\
\text { applied for } 24 \mathrm{~h} \text { to target } \\
\text { Improved BNCU delivery }\end{array}$ & [112] \\
\hline Yang et al., 2012 & Sonovue & Rat F98 glioma model & $\begin{array}{l}\text { Evans Blue [960 Da *], Om- } \\
\text { niscan [573 Da], } \\
\text { 99mTc-DTPA [ } 492 \mathrm{Da}]\end{array}$ & Applied SPECT/CT to monitor MB-FUS-BBB opening & {$[59]$} \\
\hline Yang et al., 2011 & Sonovue & Rat F98 glioma model & $\begin{array}{l}\text { Evans Blue }[960 \mathrm{Da} *], \mathrm{Om}- \\
\text { niscan }[573 \mathrm{Da}]\end{array}$ & $\begin{array}{l}\text { Increase in EB extravasations in sonicated brain with significant } \\
\text { EB concentration increase } \\
\text { Damage occurred after repeated sonication }\end{array}$ & {$[50]$} \\
\hline Yang et al., 2012 & Sonovue & Mice GBM-8401 model & Liposomal-DOX [70-100 nm] & $\begin{array}{l}\text { Radio-labeled liposomal-DOX to perform PK analysis in nuclear } \\
\text { imaging } \\
\text { Animals receiving the drugs followed by MB-FUS-BBB opening }\end{array}$ & [113] \\
\hline Yang et al., 2012 & Sonovue & Mice GBM-8401 model & Liposomal-DOX [70-100 nm] & $\begin{array}{l}\text { MB-FUS-BBB opening enhanced accumulation of the drug in } \\
\text { tumor cells } \\
\text { Significantly inhibited tumor growth compared with chemo- } \\
\text { therapy alone }\end{array}$ & {$[114]$} \\
\hline Ting et al., 2012 & $\begin{array}{l}\text { BCNU-load } \\
\text { ed MBs } \\
\text { (Self-made) }\end{array}$ & Rat C6 glioma model & $\begin{array}{l}\text { BCNU [214 Da], Evans Blue } \\
{\left[960 \mathrm{Da}^{*}\right]}\end{array}$ & $\begin{array}{l}\text { Development of BCNU drug-loaded MBs for drug delivery } \\
\text { BCNU-MBs prolonged half-life of BCNU by over } 5 \text {-fold } \\
\text { Tumor progression was successfully suppressed by BCNU-MBs } \\
\text { + FUS }\end{array}$ & [103] \\
\hline
\end{tabular}




\begin{tabular}{|c|c|c|c|c|c|}
\hline Fan et al, 2013 & $\begin{array}{l}\text { Antiangio- } \\
\text { gen- } \\
\text { ic-BCNU } \\
\text { loaded } \\
\text { MBs } \\
\text { (Self-made) }\end{array}$ & Rat C6 glioma model & $\begin{array}{l}\text { VEGF-R2 Abs [150 kDa], } \\
\text { BCNU [214 Da], Evans Blue } \\
{\left[960 \mathrm{Da}^{*}\right]}\end{array}$ & $\begin{array}{l}\text { Development of VEGF-R2-conjugated BCNU-loaded MBs for } \\
\text { targeted drug delivery } \\
\text { VEGF-R2 targeting enhanced local BCNU delivery } \\
\text { Combined with MB-FUS-BBB opening significantly improved } \\
\text { tumor progression control and prolonged animal survival }\end{array}$ & [104] \\
\hline Fan et al, 2013 & $\begin{array}{l}\text { SPIO-DOX } \\
\text { loaded } \\
\text { MBs } \\
\text { (Self-made) }\end{array}$ & Rat C6 glioma model & $\begin{array}{l}\text { BCNU [214 Da], Evans Blue } \\
{\left[960 \mathrm{Da}^{*}\right], \text { DOX [543 Da], }}\end{array}$ & $\begin{array}{l}\text { Development of SPIO-conjugated DOX-loaded MBs for } \\
\text { theranostic application } \\
\text { SPIO-DOX-MBs combined with MT to perform active targeting } \\
\text { during MB-FUS-BBB opening procedure } \\
\text { Further enhanced local accumulation of DOX } \\
\text { Serve as dual-imaging contrast agent in MRI and ultrasonogra- } \\
\text { phy }\end{array}$ & [105] \\
\hline Wei et al, 2013 & Sonovue & Rat 9L glioma model & $\begin{array}{l}\text { Temozolomide (TMZ) [194 } \\
\text { Da] }\end{array}$ & $\begin{array}{l}\text { CSF/plasma concentration of TMZ significantly increased from } \\
22 \text { to } 39 \% \text { after MB-FUS treatment } \\
\text { MB-FUS + TMZ provide better tumor progression control and } \\
\text { animal median survival improved by } 72 \%\end{array}$ & [88] \\
\hline Aryal et al, 2013 & Optison & Rat 9L glioma model & Liposomal-Dox [70-100 nm] & $\begin{array}{l}\text { Three weekly treatment sessions of MB-FUS + liposomal-DOX } \\
\text { treatment provide complete tumor supression and improve } \\
\text { animal survival nearly } 100 \%\end{array}$ & {$[80]$} \\
\hline
\end{tabular}

\section{Novel Multifunction MBs Facilitate MB-FUS BBB Opening for Brain Tumor Therapy}

MB-FUS BBB opening for brain tumor therapy has employed not only commercial agents but also newly designed MBs. Here we review our recent work related to the concept and design of three different types of multifunction MB for FUS-enhanced brain tumor drug delivery (Figs. 3, 4).

\section{I Concept of novel multifunction MBs}

The concept of therapeutic agents being encapsulated in or conjugated with MBs has been developed over the past few years. In addition to the synergistic effects of ultrasound and MBs to enhance the permeability of biological barriers such as cell membranes, small blood vessels, and the BBB, as discussed above, MBs can serve as protective drug carriers. Encapsulating unstable agents protects them from degradation in blood, thus prolonging their half-lives in vivo, improving treatment efficacy, and lowering the required dose [89]. Another advantage is that the encapsulated agents can be released during the ultrasound-triggered MB destruction process. Chemotherapeutic drugs can thus be directly and specifically delivered to target tissues via ultrasound-mediated perforations, whereas the uptake of the drugs by non-target tissues is reduced. The encapsulated agents are conjugated close to the shell of MBs, increasing the opportunity for microstreams, shock waves, and microjets to drive them toward the tissues and enhance their uptake in the ultrasound-treated region [26]. Since MBs act as ultrasound contrast agents, the drug delivery process can also be concurrently monitored by detecting the drug-loaded MBs [90].
Several strategies have been proposed for incorporating therapeutic agents in MB carriers [91, 92], including attachment to the outer shell surface, embedding within the shell, dissolving hydrophobic drugs in the oily layer between the gas core and shell, and linking them to the shell, as for example via streptavidin-biotin interactions. An example of the attachment of agents to the outer shell is non-covalent binding of negatively charged nucleic acids to the outer positively charged lipid shell of MBs for ultrasound-mediated gene delivery [93]. Although the payload of nucleic acids could be improved by increasing the amount of positively charged lipids, the presence of excessive charged lipids would disrupt lipid packing, resulting in higher surface tension and subsequently lower MB stability. Instead, a structure consisting of multilayered nucleic acids and positively charged poly-L-lysine was constructed to increase the nucleic acid loading capacity [94].

Drugs can be embedded in MBs by simply adding them during $\mathrm{MB}$ preparation. However, the degree of drug loading is rather limited in this approach, and it is influenced by the polarity of the drug, with hydrophobic molecules being preferentially packaged. In contrast, the design of acoustically active liposomes with an oil layer between the gas core and lipid has allowed encapsulation of hydrophobic drugs at a high loading capacity within this oil layer [94]. However, high ultrasound intensities are required to trigger the release of such encapsulated drugs [95].

Lastly, drugs can be pre-incorporated into carriers such as liposomes, micelles, or microspheres, and these structures can then be easily attached to lipid MBs, usually via avidin-biotin interactions [96]. Such advanced MB complexes have extremely high drug loading capacities and the advantage of being able to encapsulate both hydrophilic and hydrophobic drugs. 


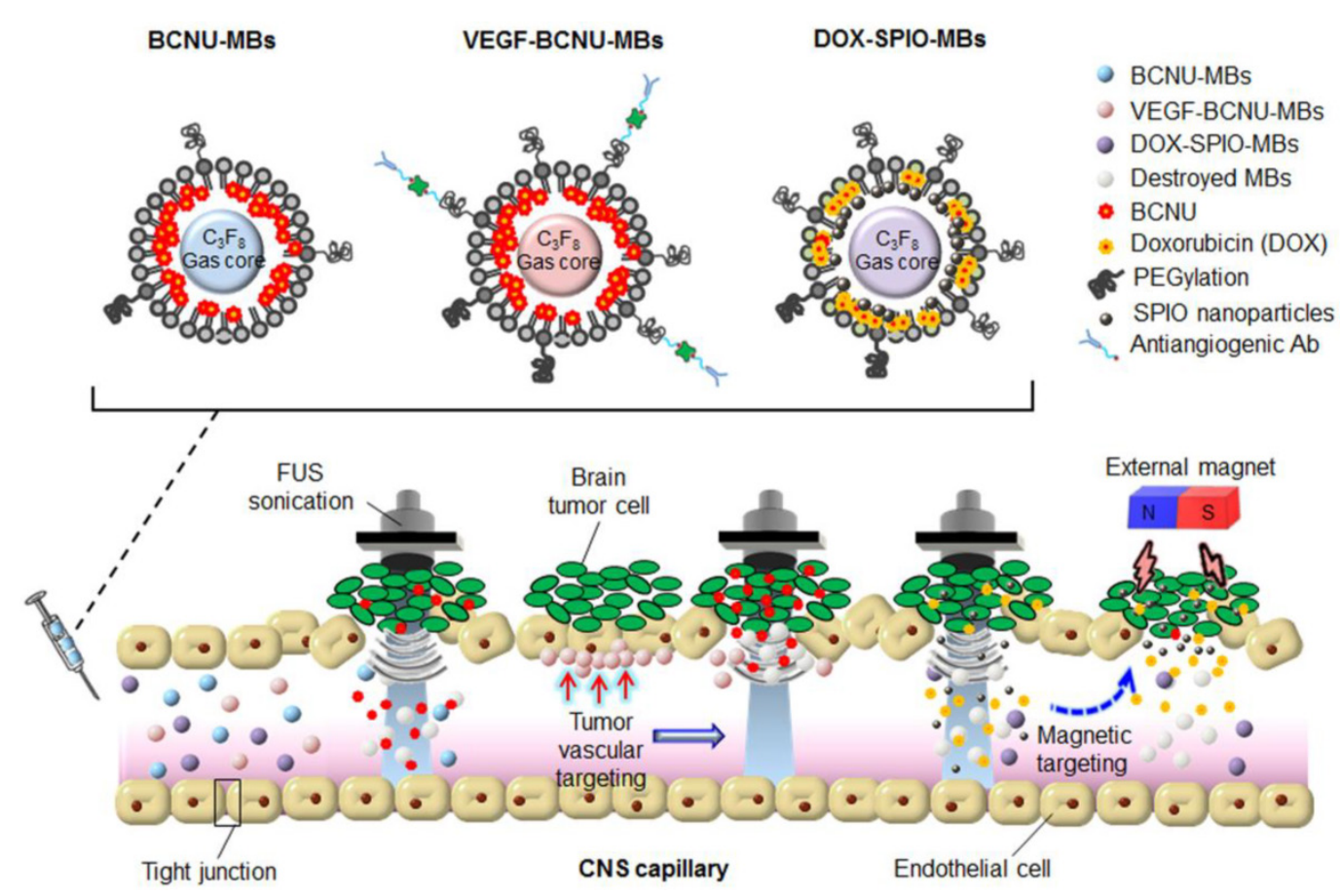

Fig. 3. Application of multifunction microbubbles for focused-ultrasound-induced brain tumor drug delivery.
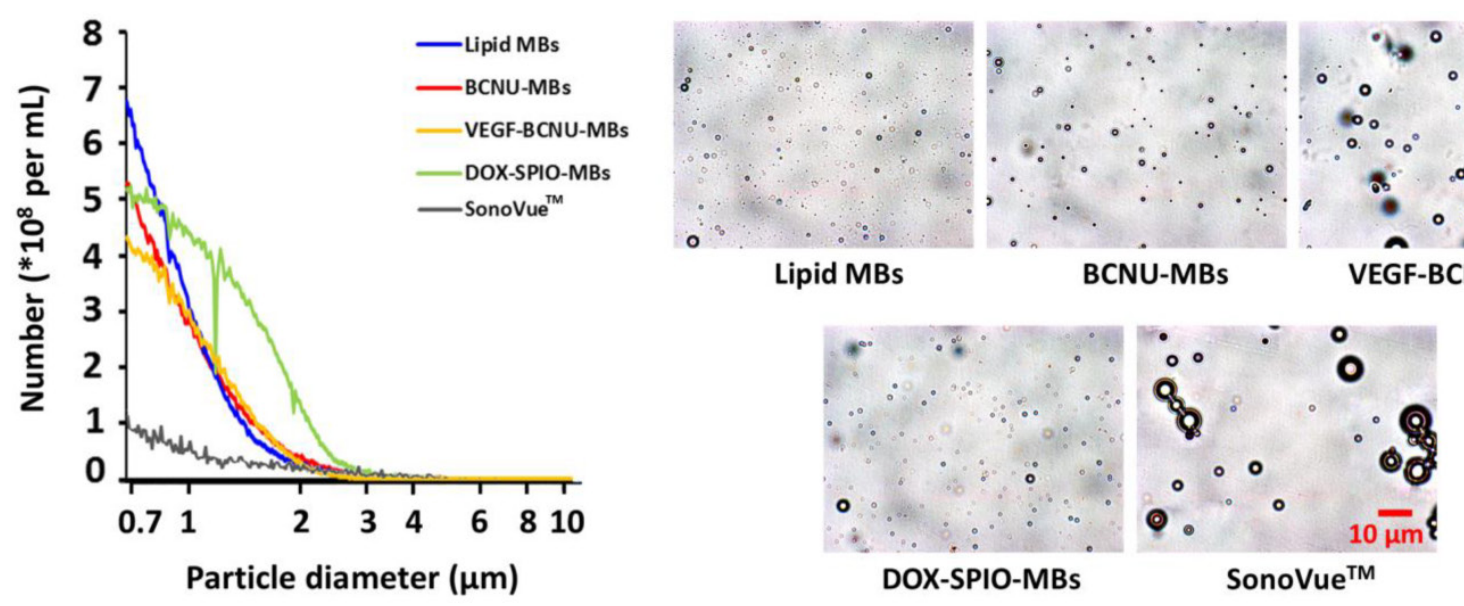

Fig. 4. Size distribution and microscopy images of microbubbles.

The effectiveness of ultrasound molecular theranostics could be improved by exploiting the nonlinear behaviors (e.g., cavitation dose, resonance frequency, or fragmentation threshold) of MBs. The resonance frequency and magnitude of the radiation force for targeting efficiency enhancement from the ultrasound-excited MBs relate to MBs size [97]. Furthermore, insonation acoustic pressure that can induce MBs fragmentation is also size-dependent [98-99]. Thus, controlling the size distribution of multifunctional MBs is crucial for most ultrasound theranostics applications [100]. Multifunction MBs were designed to have similar but with a smaller and more mono-dispersed dimension with the considerations of: maintaining sufficient nonlinear responses under therapeutic/imaging ultrasound frequency excitation, safety improvement to reduce erythrocyte extravasations, and optimization of payload of drug molecules or targeting ligands [47, 48].

\subsection{FUS-enhanced brain tumor drug delivery using BCNU-loaded MBs}

While MB-FUS-mediated BBB disruption enhances the delivery of $\mathrm{BCNU}$ to brain tumors, the short half-life of BCNU (20-50 min in vitro and less than 15 min in vivo) still intrinsically limits its efficacy after systemic application [101, 102]. A lipid-shell-based and BCNU-loaded MB (BCNU-MB; Fig. 3) was therefore proposed, which could not only serve as a drug-carrying vehicle to protect $\mathrm{BCNU}$ from rapid degradation, but could also be activated 
by FUS to concurrently achieve BBB opening and trigger the local release of $\mathrm{BCNU}$ [103].

Quantification in normal rats showed that encapsulation of BCNU in MBs prolonged its circulatory half-life by fivefold (from 13.5 to $67.5 \mathrm{~min}$ ). Compared to traditional IV BCNU administration, synergistically functioning BCNU-MB+FUS (frequency $=1 \mathrm{MHz}$, acoustic pressure $=0.5 \mathrm{MPa}$, burst length $=5 \mathrm{~ms}$, PRF $=5 \mathrm{~Hz}$, and sonication duration $=60 \mathrm{~s}$ ) significantly enhanced drug delivery by 4.2 -fold (from $4.2 \pm 0.2 \mu \mathrm{g}$ to $17.9 \pm 1.1 \mu \mathrm{g}$, mean $\pm \mathrm{SD}$ ). The concentration of $\mathrm{BCNU}$ was 3.3-fold higher in the sonicated brain than in the contralateral unsonicated brain $(5.4 \pm 0.4 \mu \mathrm{g})$. The cytotoxic effects of encapsulating BCNU were also studied by examining its accumulation in the liver and evaluating liver function. We found that loading $\mathrm{BCNU}$ in MBs lowered drug deposition in the liver by 4.8-fold, from $113.6 \pm 3.6$ to $23.9 \pm 3.6 \mu \mathrm{g}$, and also lowered aspartate aminotransferase and alanine aminotransferase levels compared to the BCNU-alone group, demonstrating that $\mathrm{BCNU}-\mathrm{MBs}$ have the potential to reduce liver toxicity and damage.

Synergistic effects between BCNU-MBs and FUS led to an early improvement in treatments of tumor-implanted rats. Tumors in the control group progressed rapidly from $22.1 \pm 17.6 \mathrm{~mm}^{3}$ (day 10) to $202.5 \pm 24.2 \mathrm{~mm}^{3}$ (day 31), whereas the BCNU-alone group demonstrated temporary but poor control of tumor progression $\left(12.9 \pm 9.1 \mathrm{~mm}^{3}\right.$ on day 10 , but $56.8 \pm 38.8 \mathrm{~mm}^{3}$ on day 17 and $150.8 \pm 11.5 \mathrm{~mm}^{3}$ on day 31 ). In contrast, the tumor size was only $11.0 \pm 1.0 \mathrm{~mm}^{3}$ on day 31 when using the BCNU-MB+FUS treatment.

The median survival times in the control and BCNU-alone groups were 29 and 29.5 days, respectively, demonstrating the limited capabilities of BCNU for brain tumor treatment. Nevertheless, the median survival time in the BCNU-MB+FUS group was increased to 32.5 days (a 12\% increase compared to the control and BCNU-alone groups), and the maximum survival time of animals was significantly extended to 59 days.

\subsection{FUS-enhanced brain tumor drug delivery using antiangiogenic-targeting drug-loaded MBs}

After successfully enhancing drug delivery by BCNU-MBs, targeted brain tumor delivery was attempted [104]. Vascular endothelial growth factor receptor 2 (VEGF-R2) is recognized to be overexpressed in the endothelial cells of gliomas, causing cell proliferation and migration and resulting in excessive angiogenesis in tumor regions. One type of MBs combining VEGF-R2-ligand conjugation and BCNU encapsulation (designated VEGF-BCNU-MBs) was thus designed to target drug delivery specifically to the sites of the tumor vasculature exhibiting overactive angiogenesis, which are characterized by overexpression of the VEGF-R2 receptor (Fig. 3).

Both immunofluorescence staining and ultrasound imaging revealed that the VEGF-BCNU-MBs exhibited prolonged retention in the blood circulation and displayed higher cumulative concentrations in the tumor region. In vivo drug accumulation in tumor tissues was significantly enhanced (by 1.9-fold) in the VEGF-BCNU-MBs+FUS BBB opening group compared to the $\mathrm{BCNU}-\mathrm{MB}+\mathrm{FUS} \mathrm{BBB}$ opening group (frequency $=1 \mathrm{MHz}$, acoustic pressure $=0.5 \mathrm{MPa}$, burst length $=5 \mathrm{~ms}, \mathrm{PRF}=5 \mathrm{~Hz}$, and sonication duration $=60 \mathrm{~s}$ ). Moreover, the tumor-to-normal-tissue concentration ratio when using the VEGF-BCNU-MBs was found to be 7, compared to 2.7 when using traditional MBs (without targeting ability) and FUS exposure. Besides, liver BCNU deposition was significantly lower in the VEGF-BCNU-MB+FUS BBB opening group than in the $\mathrm{BCNU}-\mathrm{MB}+\mathrm{FUS} \mathrm{BBB}$ opening group.

The antitumor efficacy was investigated in tumor-bearing rats. Tumors in the untreated groups grew rapidly. Neither the VEGF-R2 targeting ligand alone nor targeting MBs without BCNU (VEGF-MB) combined with FUS BBB opening provided effective control of tumor progression, although transient suppression of tumor progression was observed in the $\mathrm{BCNU}-$ alone and $\mathrm{BCNU}-\mathrm{MB}+\mathrm{FUS}$ groups. It was clear that tumor suppression was greatest when using VEGF-BCNU-MB+FUS BBB opening.

Animal survival was not improved in the BCNU-alone, VEGF-MB+FUS BBB opening, and $B C N U-M B+F U S B B B$ opening groups relative to the control group (median survival times of 23, 22.5, 18.5, and 19 days, respectively). The VEGF-R2 targeting ligand appeared to prolong survival (median survival time of 26 days), while survival was further prolonged in the VEGF-BCNU-MB+FUS BBB opening group (median survival time of 42 days).

\subsection{FUS-enhanced brain tumor drug delivery using theranostic MBs}

For the treatment of gliomas, drugs not only need to be effectively packaged in microcarriers, but their dynamics, distribution, and accumulation at the target site also need to be monitored in vivo. However, even when they are administered concurrently, therapeutic agents and biological probes can perform diverse pharmacodynamic behaviors, implying that a separate probe may actually not reflect the true drug distribution. A DOX-loaded and SPIO-nanoparticleconjugated phospholipid-based $\mathrm{MB}$ structure (DOX-SPIO-MB) was therefore designed to concurrently achieve BBB opening and delivery of therapeu- 
tic agent, while serving as a dual contrast agent in both ultrasound imaging and MRI modalities for direct confirmation of drug quantification/deposition (Fig. 3) [105].

SPIO nanoparticles have been approved for use in clinical diagnosis as an MRI contrast agent. We previously confirmed that FUS BBB opening can be monitored with the aid of SPIO nanoparticles (frequency $=400 \mathrm{kHz}$, acoustic pressure $=0.62 \mathrm{MPa}$, burst length $=10 \mathrm{~ms}, \mathrm{PRF}=1 \mathrm{~Hz}$, and sonication duration = $120 \mathrm{~s}$ ). Furthermore, the application of an external magnetic force to SPIO is a potential way to achieve active magnetic targeting (MT) to specific tumor regions [106]. IV administered DOX-SPIO-MBs exhibited excellent contrast capability in vivo, with a $25.4 \%$ enhancement for ultrasound and a $40.2 \%$ decrease for MRI, respectively. Treating tumor-implanted rats with DOX-SPIO-MBs followed by FUS sonication resulted in a 2.1-fold increase in DOX deposition at the brain tumor relative to normal brain tissue (frequency $=400 \mathrm{kHz}$, acoustic pressure $=325 \mathrm{kPa}$, burst length $=$ $2.5 \mathrm{~ms}, \mathrm{PRF}=1 \mathrm{~Hz}$, and sonication duration $=90 \mathrm{~s})$. In contrast, free DOX alone did not result in effective drug deposition in tumor regions. The delivery of SPIO to brain tumors was also investigated by inductively coupled plasma MS, which revealed that the SPIO accumulation capability was highly dependent on the concentration of administered DOX-SPIO-MBs. Similar to DOX delivery, the DOX-SPIO-MB+FUS BBB opening strategy improved SPIO delivery to brain tumors (by 2.7-fold, $11.9 \pm 0.9 \mathrm{mg} / \mathrm{g}$ tissue). Furthermore, combined FUS exposure and MT provided the most significant SPIO accumulation enhancement in tumor sites (by 4.0 -fold, $15.3 \pm 0.7 \mathrm{mg} / \mathrm{g}$ tissue).

In vivo drug delivery to the tumor site using DOX-SPIO-MB+FUS BBB opening was monitored by detecting SPIO as hypointense signal-loss regions in contrast-enhanced MRI using a sequence with heavy $\mathrm{T}^{*}$ weighting. A gradual enhancement of SPIO accumulation was observed in tumor areas after performing MT for $40 \mathrm{~min}$ following the BBB opening process. The total SPIO deposition was increased significantly, by $22.4 \%$ (note that $12 \%$ deposition was achieved in groups without MT).

The SPIO nanoparticles can be detected by MRI, which allows the in vivo distribution of therapeutic SPIO nanoparticles to potentially be traced or even quantified under an image-guided brain tumor drug delivery procedure. Future work should be focused on correlating DOX delivery and SPIO nanoparticle quantification for clinical theranostic applications, as well as modifying ligands so that they target DOX-SPIO-MBs for use in multiactive targeting.

\section{Conclusion and Perspective}

MBs not only serve as a diagnostic contrast agent for ultrasound imaging, but also provide the potential for brain drug delivery when combined with focused ultrasound. Here we have reviewed the application of MBs with FUS to temporarily open the $\mathrm{BBB}$ as a new strategy for delivering therapeutic agents to the brain. Lipid-shell MBs respond strongly to ultrasound, allowing MB-FUS BBB opening to be performed using commercial diagnostic MBs. We reviewed the current progress in MB-FUS-enhanced chemotherapeutic agent delivery for brain tumor treatment. The design of multifunctional MBs has further expanded the potential of this treatment approach by integrating BBB opening with concurrent drug release, active targeting, or even theranostic features.

MB-FUS BBB opening serves as a promising method for non-invasively and locally enhancing the targeted delivery of therapeutic agents into CNS tumor regions, providing the potential to improve the treatment efficacy of chemotherapy. Doxil has been approved for the clinical use for ovarian tumors, and TMZ as well as BCNU are already clinically approved chemotherapeutic drugs for brain tumor treatment, suggesting that the enhanced delivery of these drugs achieved by MB-FUS BBB opening is highly clinically relevant. Moreover, the use of multifunction MBs that encapsulate chemotherapeutic drugs, with antiangiogenic targeting, as well as magnetic-sensitive modifications provide many new opportunities to further improve the capability of enhanced drug delivery via MB-FUS BBB opening, and bring new research directions toward realizing noninvasive brain drug delivery for improving brain tumor therapy.

However, notwithstanding the advantages of MB-FUS BBB opening, it has also been suspected that the interaction between MBs and FUS may produce unnecessary side effects, for example erythrocyte extravasations, intracerebral micro-hemorrhages, edema, neuron injury, cell apoptosis, and inflammation, which could be arisen by over-excitation of ultrasound (e.g. excessive acoustic pressure or excessive sonication duration) or over dosages of microbubbles [73, 82, 107-110]. As research on MB-FUS BBB opening in enhanced brain drug delivery progresses, it is expected that useful insights for the control of the above-mentioned parameter for BBB disruption will be further investigated.

\section{Acknowledgments}

We thank the National Science Council of Taiwan for grants 101-3011-P-033-003 and 101-2627-M-007-001, and the National Tsing Hua 
University (grant 102N2046E1) for their financial support.

\section{Competing Interests}

The authors have declared that no competing interest exists.

\section{References}

1. Jemal A, Siegel R, Ward E, Murray T, Xu J, Smigal C, et al. Cancer statistics. CA Cancer J Clin. 2006;56(2):106-30.

2. Behin A, Hoang-Xuan K, Carpentier AF, Delattre JY. Primary brain tumours in adults. Lancet. 2003;361(9354):323-31.

3. Grossman SA, Norris LK. Adjuvant and neoadjuvant treatment for primary brain tumors in adults. Semin Oncol. 1995;22(6):530-9.

4. Galanis E, Buckner J. Chemotherapy for high-grade gliomas. Br J Cancer. 2000;82(8):1371-80.

5. Grossman SA, Batara JF. Current management of glioblastoma multiforme. Semin Oncol. 2004;31(5):635-44.

6. Grossman SA, O'Neill A, Grunnet M, Mehta M, Pearlman JL, Wagner H, et al. Phase III study comparing three cycles of infusional carmustine and cisplatin followed by radiation therapy with radiation therapy and concurrent carmustine in patients with newly diagnosed supratentorial glioblastoma multiforme: Eastern Cooperative Oncology Group Trial 2394. J Clin Oncol. 2003;21(8):1485-91.

7. Rapoport SI. Blood-brain barrier in physiology and medicine. New York: Raven Press. 1976

8. Staddon JM, Rubin LL. Cell adhesion, cell junctions and the blood-brain barrier. Curr Opin Neurobiol. 1996;6(5):622-7.

9. Pardridge WM. Drug and gene delivery to the brain: the vascular route. Neuron. 2002;36(4):555-8.

10. Ewing JR, Brown SL, Lu M, Panda S, Ding G, Knight RA, et al. Model selection in magnetic resonance imaging measurements of vascular permeability: Gadomer in a 9L model of rat cerebral tumor. J Cereb Blood Flow Metab. 2006;26(3):310-20.

11. Neuwelt EA, Barnett PA, Bigner DD, Frenkel EP. Effects of adrenal cortical steroids and osmotic blood-brain barrier opening on methotrexate delivery to gliomas in the rodent: the factor of the blood-brain barrier. Proc Natl Acad Sci US A. 1982;79(14):4420-3.

12. Neuwelt EA, Frenkel EP, D'Agostino AN, Carney DN, Minna JD, Barnett PA, et al. Growth of human lung tumor in the brain of the nude rat as a model to evaluate antitumor agent delivery across the blood-brain barrier. Cancer Res. 1985;45:2827-33

13. Groothuis DR, Fischer JM, Lapin G, Bigner DD, Vick NA. Permeability of different experimental brain tumor models to horseradish peroxidase. J Neuropathol Exp Neurol. 1982;41(2):164-85.

14. Burger PC. The anatomy of astrocytomas. Mayo Clin Proc. 1987;62(6):527-9.

15. Halperin EC, Burger PC, Bullard DE. The fallacy of the localized supratentorial malignant glioma. Int $\mathrm{J}$ Radiat Oncol Biol Phys. 1988;15(2):505-9.

16. Shapiro WR, Green SB, Burger PC, Selker RG, VanGilder JC, Robertson JT, et al. A randomized comparison of intra-arterial versus intravenous $\mathrm{BCNU}$, with or without intravenous 5-fluorouracil, for newly diagnosed patients with malignant glioma. J Neurosurg. 1992;76(5):772-81.

17. Judy KD, Olivi A, Buahin KG, Domb A, Epstein JI, Colvin OM, et al. Effectiveness of controlled release of a cyclophosphamide derivative with polymers against rat gliomas. J Neurosurg. 1995;82(3):481-6.

18. Westphal M, Hilt DC, Bortey E, Delavault P, Olivares R, Warnke PC, et al. A phase 3 trial of local chemotherapy with biodegradable carmustine (BCNU) wafers (Gliadel wafers) in patients with primary malignant glioma. Neuro Oncol. 2003;5(2):79-88

19. Gallego JM, Barcia JA, Barcia-Mariño C. Fatal outcome related to carmustine implants in glioblastoma multiforme. Acta Neurochir (Wien). 2007;149(3):261-5; discussion 265.

20. Bobo RH, Laske DW, Akbasak A, Morrison PF, Dedrick RL, Oldfield EH. Convection-enhanced delivery of macromolecules in the brain. Proc Natl Acad Sci U S A. 1994:91(6):2076-80.

21. Doolittle ND, Miner ME, Hall WA, Siegal T, Jerome E, Osztie E, et al. Safety and efficacy of a multicenter study using intraarterial chemotherapy in conjunction with osmotic opening of the blood-brain barrier for the treatment of patients with malignant brain tumors. Cancer 2000;88(3):637-47.

22. Gumerlock MK, Belshe BD, Madsen R, Watts C. Osmotic blood-brain barrier disruption and chemotherapy in the treatment of high grade malignant glioma: patient series and literature review. J Neurooncol. 1992;12(1):33-46.

23. Neuwelt EA, Frenkel EP, Gumerlock MK, Braziel R, Dana B, Hill SA. Developments in the diagnosis and treatment of primary CNS lymphoma. A prospective series. Cancer 1986;58(8):1609-20.

24. Gramiak R, Shah PM. Echocardiography of the aortic root. Invest Radiol. 1968;3(5):356-66.

25. Quaia E. Microbubble ultrasound contrast agents: an update. Eur Radiol. 2007;17(8):1995-2008.
26. Frinking PJ, Bouakaz A, Kirkhorn J, Ten Cate FJ, de Jong N. Ultrasound contrast imaging: current and new potential methods. Ultrasound Med Biol. 2000;26(6):965-75

27. Dayton PA, Ferrara KW. Targeted imaging using ultrasound. J Magn Reson Imaging. 2002;16(4):362-77.

28. Foster FS, Burns PN, Simpson DH, Wilson SR, Christopher DA, Goertz DE. Ultrasound for the visualization and quantification of tumor microcirculation. Cancer Metastasis Rev. 2000;19(1-2):131-8.

29. Harvey CJ, Blomley MJ, Eckersley RJ, Cosgrove DO, Patel N, Heckemann RA, et al. Hepatic malignancies: improved detection with pulse-inversion US in late phase of enhancement with SH U 508A-early experience. Radiology 2000;216(3):903-8

30. Arnold JR, Karamitsos TD, Pegg TJ, Francis JM, Olszewski R, Searle N, et al. Adenosine stress myocardial contrast echocardiography for the detection of coronary artery disease: a comparison with coronary angiography and cardiac magnetic resonance. JACC Cardiovascular imaging. 2010;3(9):934-43.

31. Correas J, Hélénon O, Moreau JF. Contrast-enhanced ultrasonography of native and transplanted kidney diseases. Eur Radiol. 1999;9 Suppl 3:S394-400.

32. Kang ST, Yeh CK. Ultrasound microbubble contrast agents for diagnostic and therapeutic applications: current status and future design. Chang Gung Med J. 2012;35(2):125-39.

33. Juffermans LJ, Meijering DB, van Wamel A, Henning RH, Kooiman K, Emmer $\mathrm{M}$, et al. Ultrasound and microbubble-targeted delivery of therapeutic compounds: ICIN Report Project 49: Drug and gene delivery through ultrasound and microbubbles. Neth Heart J. 2009;17(2):82-6.

34. Chappell JC, Song J, Klibanov AL, Price RJ. Ultrasonic microbubble destruction stimulates therapeutic arteriogenesis via the CD18-dependent recruitment of bone marrow-derived cells. Arterioscler Thromb Vasc Biol. 2008;28(6):1117-22

35. Sboros V. Response of contrast agents to ultrasound. Adv Drug Deliv Rev. 2008;60(10):1117-36.

36. Husseini GA, Diaz de la Rosa MA, Richardson ES, Christensen DA, Pitt WG. The role of cavitation in acoustically activated drug delivery. J Control Release. 2005;107(2):253-61.

37. Basta G, Venneri L, Lazzerini G, Pasanisi E, Pianelli M, Vesentini N, et al. In vitro modulation of intracellular oxidative stress of endothelial cells by diagnostic cardiac ultrasound. Cardiovasc Res. 2003;58(1):156-61.

38. Mitragotri S. Healing sound: the use of ultrasound in drug delivery and other therapeutic applications. Nat Rev Drug Discov. 2005;4(3):255-60.

39. Dalecki D. Mechanical bioeffects of ultrasound. Annu Rev Biomed Eng. 2004;6:229-48

40. Liu $Y$, Yi S, Zhang J, Fang $Z$, Zhou F, Jia W, et al. Effect of Microbubble-enhanced Ultrasound on Prostate Permeability: A Potential Therapeutic Method for Prostate Disease. Urology 2013;81(4):921.e1-7.

41. Karshafian R, Bevan PD, Williams R, Samac S, Burns PN. Sonoporation by ultrasound-activated microbubble contrast agents: effect of acoustic exposure parameters on cell membrane permeability and cell viability. Ultrasound Med Biol. 2009;35(5):847-60.

42. van Wamel A, Kooiman K, Emmer M, ten Cate FJ, Versluis M, de Jong N. Ultrasound microbubble induced endothelial cell permeability. J Control Release. 2006;116(2):e100-2

43. Bekeredjian R, Kroll RD, Fein E, Tinkov S, Coester C, Winter G, et al Ultrasound targeted microbubble destruction increases capillary permeability in hepatomas. Ultrasound Med Biol. 2007;33(10):1592-8.

44. Hynynen K, McDannold N, Sheikov NA, Jolesz FA, Vykhodtseva N. Local and reversible blood-brain barrier disruption by noninvasive focused ultrasound at frequencies suitable for trans-skull sonications. Neuroimage 2005;24(1):12-20.

45. Hynynen K, McDannold N, Vykhodtseva N, Jolesz FA. Noninvasive MR imaging-guided focal opening of the blood-brain barrier in rabbits. Radiology 2001;220(3):640-6.

46. Hynynen K, McDannold N, Vykhodtseva N, Jolesz FA. Non-invasive opening of BBB by focused ultrasound. Acta Neurochir (Wien). 2003;86:555-8.

47. Choi JJ, Feshitan JA, Baseri B, Wang S, Tung YS, Borden MA, et al. Microbubble-size dependence of focused ultrasound-induced blood-brain barrier opening in mice in vivo. IEEE Trans Biomed Eng. $2010 ; 57(1): 145-54$

48. Fan $\mathrm{CH}$, Liu HL, Yen TC, Yeh CK. Focused ultrasound with submicron bubbles producing inertial cavitation suppression in blood-brain barrier opening application. Proc IEEE Ultrason Symp. 2011*1997-2000.

49. Liu HL, Wai YY, Chen WS, Chen JC, Hsu PH, Wu XY, et al. Hemorrhage detection during focused-ultrasound induced blood-brain-barrier opening by using susceptibility-weighted magnetic resonance imaging. Ultrasound Med Biol. 2008;34(4):598-606.

50. Yang FY, Lin GL, Horng SC, Chang TK, Wu SY, Wong TT, et al. Pulsed high-intensity focused ultrasound enhances the relative permeability of the lood-tumor barrier in a glioma-bearing rat model. IEEE Trans Ultrason Ferroelectr Freq Control. 2011;58(5):964-70

51. Hynynen K, McDannold N, Vykhodtseva N, Raymond S, Weissleder R, Jolesz $\mathrm{FA}$, et al. Focal disruption of the blood-brain barrier due to $260-\mathrm{kHz}$ ultrasound bursts: a method for molecular imaging and targeted drug delivery. J Neurosurg. 2006;105(3):445-54.

52. Raymond SB, Skoch J, Hynynen K, Bacskai BJ. Multiphoton imaging of ultrasound/Optison mediated cerebrovascular effects in vivo. J Cereb Blood Flow Metab. 2007;27(2):393-403 
53. Choi JJ, Pernot M, Small SA, Konofagou EE. Noninvasive, transcranial and localized opening of the blood-brain barrier using focused ultrasound in mice. Ultrasound Med Biol. 2007;33(1):95-104.

54. Choi JJ, Selert K, Gao Z, Samiotaki G, Baseri B, Konofagou EE. Noninvasive and localized blood-brain barrier disruption using focused ultrasound can be achieved at short pulse lengths and low pulse repetition frequencies. J Cereb Blood Flow Metab. 2011;31(2):725-37.

55. Choi JJ, Wang S, Brown TR, Small SA, Duff KE, Konofagou EE. Noninvasive and transient blood-brain barrier opening in the hippocampus of Alzheimer's double transgenic mice using focused ultrasound. Ultrason imaging. 2008;30(3):189-200.

56. Choi JJ, Wang S, Tung YS, Morrison B 3rd, Konofagou EE. Molecules of various pharmacologically-relevant sizes can cross the ultrasound-induced blood-brain barrier opening in vivo. Ultrasound Med Biol. 2010;36(1):58-67.

57. Sheikov N, McDannold N, Sharma S, Hynynen K. Effect of focused ultrasound applied with an ultrasound contrast agent on the tight junctional integrity of the brain microvascular endothelium. Ultrasound Med Biol. 2008;34(7):1093-104

58. Lin KJ, Liu HL, Hsu PH, Chung YH, Huang WC, Chen JC, et al. Quantitative micro-SPECT/CT for detecting focused ultrasound-induced blood-brain barrier opening in the rat. Nucl Med Biol. 2009;36(7):853-61.

59. Yang FY, Wang HE, Lin GL, Teng MC, Lin HH, Wong TT, et al. Micro-SPECT/CT-based pharmacokinetic analysis of 99mTc-diethylenetriaminepentaacetic acid in rats with blood-brain barrier disruption induced by focused ultrasound. J Nucl Med. 2011;52(3):478-84.

60. Liu HL, Hsu PH, Chu PC, Wai YY, Chen JC, Shen CR, et al. Magnetic resonance imaging enhanced by superparamagnetic iron oxide particles: usefulness for distinguishing between focused ultrasound-induced blood-brain barrier disruption and brain hemorrhage. J Magn Reson Imaging. 2009;29(1):31-8.

61. Burgess A, Huang Y, Querbes W, Sah DW, Hynynen K. Non-invasive delivery of small interfering ribonucleic acid for reduction of Huntingtin expression in the brain is achieved using focused ultrasound to disrupt the blood-brain barrier. J Acoust Soc Am. 2013;133(5):3408.

62. Howles GP, Bing KF, Qi Y, Rosenzweig SJ, Nightingale KR, Johnson GA. Contrast-enhanced in vivo magnetic resonance microscopy of the mouse brain enabled by noninvasive opening of the blood-brain barrier with ultrasound. Magn Reson Med. 2010;64(4):995-1004.

63. Wang PH, Liu HL, Hsu PH, Lin CY, Wang CR, Chen PY, et al. Gold-nanorod contrast-enhanced photoacoustic micro-imaging of focused-ultrasound induced blood-brain-barrier opening in a rat model. J Biomed Opt. 2012;17(6):061222

64. Treat LH, McDannold N, Vykhodtseva N, Zhang Y, Tam K, Hynynen K. Targeted delivery of doxorubicin to the rat brain at therapeutic levels using MRI-guided focused ultrasound. Int J Cancer. 2007;121(4):901-7.

65. Wang F, Cheng Y, Mei J, Song Y, Yang YQ, Liu Y, et al. Focused ultrasound microbubble destruction-mediated changes in blood-brain barrier permeability assessed by contrast-enhanced magnetic resonance imaging. J Ultrasound Med. 2009;28(11):1501-9.

66. Xie F, Boska MD, Lof J, Uberti MG, Tsutsui JM, Porter TR. Effects of transcranial ultrasound and intravenous microbubbles on blood brain barrier permeability in a large animal model. Ultrasound Med Biol. 2008;34(12):2028-34.

67. Kinoshita M, McDannold N, Jolesz FA, Hynynen K. Targeted delivery of antibodies through the blood-brain barrier by MRI-guided focused ultrasound. Biochem Biophys Res Commun. 2006;340(4):1085-90.

68. Mei J, Cheng Y, Song Y, Yang Y, Wang F, Liu Y, et al. Experimental study on targeted methotrexate delivery to the rabbit brain via magnetic resonance imaging-guided focused ultrasound. Journal of ultrasound in medicine. J Ultrasound Med. 2009;28(7):871-80

69. Jordão JF, Ayala-Grosso CA, Markham K, Huang Y, Chopra R, McLaurin J, et al. Antibodies targeted to the brain with image-guided focused ultrasound reduces amyloid-beta plaque load in the TgCRND8 mouse model of Alzheimer's disease. PLoS One. 2010;5(5):e10549.

70. Raymond SB, Treat LH, Dewey JD, McDannold NJ, Hynynen K, Bacskai BJ. Ultrasound enhanced delivery of molecular imaging and therapeutic agents in Alzheimer's disease mouse models. PLoS One. 2008;3(5):e2175.

71. Liu HL, Chen PY, Yang HW, Wu JS, Tseng IC, Ma YJ, et al. In vivo MR quantification of superparamagnetic iron oxide nanoparticle leakage during low-frequency-ultrasound-induced blood-brain barrier opening in swine. J Magn Reson Imaging. 2011;34(6):1313-24.

72. Liu HL, Wai YY, Hsu PH, Lyu LA, Wu JS, Shen CR, et al. In vivo assessment of macrophage CNS infiltration during disruption of the blood-brain barrier with focused ultrasound: a magnetic resonance imaging study. J Cereb Blood Flow Metab. 2010;30(1):177-86.

73. Yang FY, Chen YW, Chou FI, Yen SH, Lin YL, Wong TT. Boron neutron capture therapy for glioblastoma multiforme: enhanced drug delivery and antitumor effect following blood-brain barrier disruption induced by focused ultrasound. Future Oncol. 2012;8(10):1361-9.

74. Alkins RD, Brodersen PM, Sodhi RN, Hynynen K. Enhancing drug delivery for boron neutron capture therapy of brain tumors with focused ultrasound. Neuro Oncol. 2013;15(9):1225-35.

75. Burgess A, Huang Y, Querbes W, Sah DW, Hynynen K. Focused ultrasound for targeted delivery of siRNA and efficient knockdown of Htt expression. J Control Release. 2012;163(2):125-9.
76. Burgess A, Ayala-Grosso CA, Ganguly M, Jordão JF, Aubert I, Hynynen K. Targeted delivery of neural stem cells to the brain using MRI-guided focused ultrasound to disrupt the blood-brain barrier. PLoS One. 2011;6(11):e27877.

77. Alkins R, Burgess A, Ganguly M, Francia G, Kerbel R, Wels WS, et al. Focused ultrasound delivers targeted immune cells to metastatic brain tumors. Cancer Res. 2013;73(6):1892-9.

78. Treat LH, Zhang Y, McDannold N, Hynynenet K. Impact of focused ultrasound-enhanced drug delivery on survival in rats with glioma. AIP Conf. Proc. 2008;1113:443-7.

79. Treat LH, McDannold N, Zhang Y, Vykhodtseva N, Hynynen K. Improved anti-tumor effect of liposomal doxorubicin after targeted blood-brain barrier disruption by MRI-guided focused ultrasound in rat glioma. Ultrasound Med Biol. 2012;38(10):1716-25.

80. Aryal M, Vykhodtseva N, Zhang YZ, Park J, McDannold N. Multiple treatments with liposomal doxorubicin and ultrasound-induced disruption of blood-tumor and blood-brain barriers improve outcomes in a rat glioma model. J Control Release. 2013;169(1-2):103-11.

81. Liu HL, Hua MY, Chen PY, Chu PC, Pan CH, Yang HW, et al. Blood-brain barrier disruption with focused ultrasound enhances delivery of chemotherapeutic drugs for glioblastoma treatment. Radiology 2010;255(2):415-25.

82. Foye WO. Cancer chemotherapeutic agents. Washington, DC: American Chemical Society, 1995

83. Fine HA, Dear KB, Loeffler JS, Black PM, Canellos GP. Meta-analysis of radiation therapy with and without adjuvant chemotherapy for malignant gliomas in adults. Cancer 1993;71(8):2585-97.

84. Kim H, Likhari P, Parker D, Statkevich P, Marco A, Lin CC, et al. High-performance liquid chromatographic analysis and stability of anti-tumor agent temozolomide in human plasma. J Pharm Biomed Anal. 2001;24(3):461-8.

85. Kim HK, Lin CC, Parker D, Veals J, Lim J, Likhari P, et al. High-performance liquid chromatographic determination and stability of 5-(3-methyltriazen-1-yl)-imidazo-4-carboximide, the biologically active product of the antitumor agent temozolomide, in human plasma. J Chromatogr B Biomed Sci Appl. 1997;703(1-2):225-33.

86. Baker SD, Wirth M, Statkevich P, Reidenberg P, Alton K, Sartorius SE, et al. Absorption, metabolism, and excretion of 14C-temozolomide following oral administration to patients with advanced cancer. Clin Cancer Res. 1999;5(2):309-17.

87. Stupp R, Mason WP, van den Bent MJ, Weller M, Fisher B, Taphoorn MJ, et al. Radiotherapy plus concomitant and adjuvant temozolomide for glioblastoma. N Engl J Med. 2005;352(10):987-96.

88. Wei KC, Chu PC, Wang HY, Huang CY, Chen PY, Tsai HC, et al. Focused ultrasound-induced blood-brain barrier opening to enhance temozolomide delivery for glioblastoma treatment: a preclinical study. PLoS One. 2013;8(3):e58995

89. Tachibana K, Tachibana S. The use of ultrasound for drug delivery. Echocardiography 2001;18(4):323-8

90. Ferrara K, Pollard R, Borden M. Ultrasound microbubble contrast agents: fundamentals and application to gene and drug delivery. Annu Rev Biomed Eng. 2007;9:415-47.

91. Unger EC, Porter T, Culp W, Labell R, Matsunaga T, Zutshi R. Therapeutic applications of lipid-coated microbubbles. Adv Drug Deliv Rev. 2004;56(9):1291-314.

92. Hernot S, Klibanov AL. Microbubbles in ultrasound-triggered drug and gene delivery. Adv Drug Deliv Rev. 2008;60(10):1153-66.

93. Borden MA, Caskey CF, Little E, Gillies RJ, Ferrara KW. DNA and polylysine adsorption and multilayer construction onto cationic lipid-coated microbubbles. Langmuir 2007;23(18):9401-8.

94. Unger EC, McCreery TP, Sweitzer RH, Caldwell VE, Wu Y. Acoustically active lipospheres containing paclitaxel: a new therapeutic ultrasound contrast agent. Invest Radiol. 1998;33(12):886-92.

95. Shortencarier MJ, Dayton PA, Bloch SH, Schumann PA, Matsunaga TO, Ferrara KW. A method for radiation-force localized drug delivery using gas-filled lipospheres. IEEE Trans Ultrason Ferroelectr Freq Control. 2004;51(7):822-31.

96. Lum AF, Borden MA, Dayton PA, Kruse DE, Simon SI, Ferrara KW. Ultrasound radiation force enables targeted deposition of model drug carriers loaded on microbubbles. J Control Release. 2006;111(1-2):128-34.

97. Zhao S, Borden MA, Bloch SH, Kruse DE, Ferrara KW, Dayton PA. Radiation-force assisted targeting facilitates ultrasonic molecular imaging. Mol Imaging. 2004;3(3):135-48.

98. Chin CT, Burns PN. Predicting the acoustic response of a microbubble population for contrast imaging in medical ultrasound. Ultrasound Med Biol. 2000;26(8):1293-300.

99. Morgan KE, Allen JS, Dayton PA, Chomas JE, Klibanov AL, Ferrara KW. Experimental and theoretical evaluation of microbubble behavior: effect of transmitted phase and bubble size. IEEE Trans Ultrason Ferroelectr Freq Control. 2000:47(6):1494-509.

100. Wang $\mathrm{CH}$, Yeh CK. Controlling the size distribution of lipid-coated bubbles via fluidity regulation. Ultrasound Med Biol. 2013; 39(5):882-92.

101. Loo TL, Dion RL, Dixon RL, Rallet DP. The antitumor agent, 1,3-bis(2-chloroethyl)-1-nitrosourea. J Pharm Sci. 1966;55:492e7.

102. Wheeler KT, Levin VA, Deen DF. The concept of drug dose for in vitro studies with chemotherapeutic agents. Radiat Res. 1978;76:441e58. 
103. Ting CY, Fan CH, Liu HL, Huang CY, Hsieh HY, Yen TC, et al. Concurrent blood-brain barrier opening and local drug delivery using drug-carrying microbubbles and focused ultrasound for brain glioma treatment. Biomaterials 2012;33(2):704-12.

104. Fan CH, Ting CY, Liu HL, Huang CY, Hsieh HY, Yen TC, et al. Antiangiogenic-targeting drug-loaded microbubbles combined with focused ultrasound for glioma treatment. Biomaterials 2013;34(8):2142-55.

105. Fan CH, Ting CY, Lin HJ, Wang CH, Liu HL, Yen TC, et al. SPIO-conjugated, doxorubicin-loaded microbubbles for concurrent MRI and focused-ultrasound enhanced brain-tumor drug delivery. Biomaterials 2013;34(14):3706-15.

106. Liu HL, Hua MY, Yang HW, Huang CY, Chu PC, Wu JS, et al. Magnetic resonance monitoring of focused ultrasound/magnetic nanoparticle targeting delivery of therapeutic agents to the brain. Proc Natl Acad Sci U S A. 2010;107(34):15205-10.

107. McDannold N, Vykhodtseva N, Hynynen K. Targeted disruption of the blood-brain barrier with focused ultrasound: association with cavitation activity. Phys Med Biol. 2006;51(4):793-807.

108. Tung YS, Vlachos F, Choi JJ, Deffieux T, Selert K, Konofagou EE. In vivo transcranial cavitation threshold detection during ultrasound-induced blood-brain barrier opening in mice. Phys Med Biol. 2010;55(20):6141-55.

109. Fan CH, Liu HL, Huang CY, Ma YJ, Yen TC, Yeh CK. Detection of intracerebral hemorrhage and transient blood-supply shortage in focused-ultrasound-induced blood-brain barrier disruption by ultrasound imaging. Ultrasound Med Biol. 2012;38(8):1372-82.

110. Xi G, Keep RF, Hoff JT. Mechanisms of brain injury after intracerebral haemorrhage. Lancet Neurol. 2006;5(1):53-63.

111. Liu HL, Pan CH, Ting CY, Hsiao MJ. Opening of the blood-brain barrier by low-frequency $(28-\mathrm{kHz})$ ultrasound: a novel pinhole-assisted mechanical scanning device. Ultrasound Med Biol. 2010;36(2):325-35.

112. Chen PY, Liu HL, Hua MY, Yang HW, Huang CY, Chu PC, et al. Novel magnetic/ultrasound focusing system enhances nanoparticle drug delivery for glioma treatment. Neuro Oncol. 2010;12(10):1050-60.

113. Yang FY, Wang HE, Liu RS, Teng MC, Li JJ, Lu M, et al. Pharmacokinetic analysis of 111 in-labeled liposomal Doxorubicin in murine glioblastoma after blood-brain barrier disruption by focused ultrasound. PloS One. 2012;7(9):e45468

114. Yang FY, Wong TT, Teng MC, Liu RS, Lu M, Liang HF, et al. Focused ultrasound and interleukin-4 receptor-targeted liposomal doxorubicin for enhanced targeted drug delivery and antitumor effect in glioblastoma multiforme. J Control Release. 2012;160(3):652-8 